\title{
Dealing with Snakes in Florida's Residential Areas -- Emergency Planning 1
}

Steve A. Johnson and Monica E. McGarrity ${ }^{2}$

Interactions between snakes and people and pets in Florida's residential areas are inevitable. Most of these encounters will involve one of the many species of non-venomous snakes that are native to Florida. Nonetheless, there will be times when people and pets come into contact with one of the six species of venomous snakes that live in the state. In many of these situations, a negative encounter can be avoided by simply leaving the snake alone. Attempting to harass, handle, or kill a venomous snake greatly increases your chances of being bitten, so it is critical that you adopt a "leave it be" attitude toward all venomous snakes. Nevertheless, accidents will happen, and it is important that you react appropriately, as doing so can save your life or the life of a family member (pets included). Fortunately, the risk of snakebite (venomous or non-venomous) is very small, and the risk of death from venomous snakebite is minimal. In the U.S., only 5-6 deaths each year are due to a venomous snakebite - a tenth of the number of fatalities ( 53) caused by hornet, bee, and wasp stings!
In residential areas where human-snake encounters are likely to occur, we recommend a three-part proactive approach for coexisting safely with snakes. This document provides information on the final step of this proactive approach - being prepared for a venomous snakebite emergency.

\section{"AN OUNCE OF PREVENTION IS}

\section{WORTH A POUND OF CURE”}

Prevention should be part of any snakebite emergency plan. Educating yourself and your family members about snakes will help you avoid being a victim of a bite by a snake. For tips on preventing encounters with snakes around your home, please consult the companion document in this series, "Dealing with Snakes in Florida's Residential Areas - Preventing Encounters" (http://edis.ifas.ufl.edu/UW260), as well as the document "Preventing Encounters Between Children and Snakes" (http://edis.ifas.ufl.edu/UW227). Also discourage

1. This document is WEC 222, the final document in a 4-part series entitled "Dealing with Snakes in Florida's Residential Areas", of the Department of Wildlife Ecology and Conservation, University of Florida / IFAS. First published July 2007. Michael Schaer, D.V.M., DACVIM, DACVECC, Professor and Associate Chair of the University of Florida College of Veterinary Medicine, provided expert advice on the topic of venomous snakebite and pets, reviewed this document for accuracy, and provided relevant photographs. Accompanying documents by Dr. Johnson related to dealing with snakes in a variety of settings are available through the University of Florida/EDIS at http://edis.ifas.ufl.edu/TOPIC_A23708620. A free PowerPoint presentation (with speaking notes) on the topic of venomous snake safety is available upon request from Steve A. Johnson by email - tadpole@ufl.edu.

2. Steve A. Johnson - Department of Wildlife Ecology and Conservation and Gulf Coast Research and Education Center, University of Florida IFAS/Plant City Campus, 1200 North Park Road, Plant City, FL 33563

Monica E. McGarrity - Gulf Coast Research and Education Center, University of Florida IFAS/Plant City Campus, Plant City, FL

The Institute of Food and Agricultural Sciences (IFAS) is an Equal Opportunity Institution authorized to provide research, educational information and other services only to individuals and institutions that function with non-discrimination with respect to race, creed, color, religion, age, disability, sex, sexual orientation, marital status, national origin, political opinions or affiliations. U.S. Department of Agriculture, Cooperative Extension Service, University of Florida, IFAS, Florida A. \& M. University Cooperative Extension Program, and Boards of County Commissioners Cooperating. Larry Arrington, Dean 
your pets (especially dogs) from harassing or trying to kill snakes. Modifying the behavior of your pet when you have the opportunity to do so may one day save its life.

\section{DEVELOPING A PLAN}

In order to prepare for immediate action in the event that you, someone you are with, or a pet is bitten by a venomous snake, you should develop a household or community action plan. If a person is bitten, the first step in executing this plan is to immediately call 911 for prompt medical care. If you suspect your pet has been bitten by a venomous snake, immediate medical care is also essential. Be sure that emergency numbers are prominently posted in a location accessible to all family members. These emergency numbers should include 911, your local hospital, and the Poison Control Hotline, and for pets, the appropriate veterinarians office and the Animal Poisoning Hotline. It is also a good idea to print and keep on hand maps and directions to the nearest hospital and the appropriate veterinarians office.

Additional components of an emergency action plan are outlined below. After your plan is prepared, household (or community) members should discuss it together and be aware of the following "Dos and Don'ts" of snakebite treatment, what to expect and where the emergency snakebite plan will be kept.

\section{SNAKEBITE DOs AND DON'Ts}

\section{DO --}

\section{- Seek immediate medical treatment for any snakebite-}

If a pet or someone is bitten by a snake and you cannot be $100 \%$ the bite was from a non-venomous species, assume the snake is venomous and seek immediate medical care. It is better to err on the side of caution, even if the bite is from a non-venomous snake. The only reliable way to confirm the species' identity is by getting a good look at the snake and being absolutely positive of your ability to identify Florida's snakes. Again, if there is even a remote possibility that the snake was venomous, seek immediate medical care. This is especially true for children and elderly people.
Once the 911 call has been made, call the Poison Control Center's National Hotline. Staff at these centers are trained to give guidance on the steps that need to be taken prior to the arrival of the ambulance. Provide the Poison Control Center with the name and phone number of the emergency room (ER) where the victim is being transported and request that the center have a toxicologist contact the ER. The toxicologist with the Poison Control Center is trained on how to treat victims of venomous snakebites and will consult with the doctor at the ER to ensure the victim receives the best care possible.

If you are positive that the bite is from a non-venomous snake, it is still important to treat the wound. If a human or pet is bitten by a non-venomous snake, wash the bite gently with soap and warm water. Call your family doctor or non-emergency veterinarian to schedule an appointment for a check-up - even non-venomous snakes have many harmful bacteria in their mouths, and your doctor may want to prescribe an antibiotic.

\section{- Get the victim away from the snake-}

To avoid being bitten multiple times, it is important to get the victim away from the snake. This is especially true for dogs, which may not immediately back away from a snake even after they are bitten. Do not put yourself at risk of a bite while trying to get your dog away from a venomous snake. It is not necessary to confirm the identification of the snake for adequate medical care to be administered, so do not waste valuable time attempting to catch or kill the snake.

\section{- Keep the victim warm, as comfortable as} possible, and offer reassurance-

Being bitten by a venomous snake is a very traumatic experience. Keep the victim calm, warm and as comfortable as possible - terror brought on by snakebite is often the cause of many symptoms and can complicate treatment.

- Keep a record of the victims symptoms and allergies-

Keep a record of the time of the bite and the victim's symptoms, such as nausea, vomiting, 
diarrhea, swelling, redness, numbness, drowsiness, or difficulty breathing. This will help the ER doctor and Poison Control Center toxicologist determine the severity of the bite and appropriate treatment. Also document any first aid measures administered since the bite. Be sure to give this information, as well as the time of the bite, to emergency medical personnel. Be aware of any allergies (drug, food, animal) or existing medical conditions the victim may have. Snake antivenin, which will likely be administered at the hospital to counteract the effects of the venom, is produced with the aid of horses and sheep so it is important to know if the victim has any allergies to these animals. If the victim is allergic to papaya or papain (a key ingredient in meat tenderizers) be sure to tell the attending physician or nurse. The manufacturer of one of the most commonly administered forms of antivenin, known as $\mathrm{CroFab}^{\mathrm{TM}}$, cautions against using its product on patients with allergies to papaya and papain.

- Remove bracelets, rings, and constrictive clothing-

Depending on the species and severity of the bite, swelling is likely, especially if the bite is on an extremity. Constricting jewelry and clothing can cause complications when the area of the bite swells, and should be removed.

\section{- Keep the bite area lower than the victims heart-}

If the bite is on an extremity (hand, arm, foot, leg), keep the bitten extremity immobilized in a position lower than the heart. Also keep the victim calm and limit his/her physical activity, which may speed the action of the venom.

- Wash the bite wound with soap and water-

Do this if time permits and if it is not excessively painful to the victim, but don't delay medical care in order to wash the wound.

\section{DO NOT --}

\section{- Wait for symptoms to develop-}

Although it is true that some percentage of victims of bites from venomous snakes do not develop symptoms ( 20-30\%, estimates vary), you should not wait for symptoms to develop before calling 911. Bites from Coral Snakes (as compared to pit viper bites) are often painless or only cause minimal pain and show negligible tissue damage at the bite site, and symptoms may not be immediately apparent. Again, DO NOT wait to seek medical attention!

\section{- Do not apply "traditional" remedies-}

Do not apply ice, heat, a tourniquet or electric shock, and do not attempt to make an " $\mathrm{X}$ " incision and suck out the venom. These "traditional" snakebite treatment methods can result in additional tissue damage, blood loss, or even the loss of a limb. It is also important that you do not allow the victim to take any stimulants or drink alcohol, as these substances will speed up the effects of the venom. Venom extractors, such as the Sawyer Extractor ${ }^{\circledR}$ (http://www.sawyerproducts.com/B6B.htm) may help slightly if applied within five minutes of the bite and used for thirty minutes. However, this is NOT a substitute for medical care - merely a first aid method you may try while waiting for an ambulance. Most importantly, DO NOT wait to seek medical attention; call 911! Your cell phone is your best snakebite kit.

\section{- Do not attempt to catch or kill the snake-}

Under no circumstances should you try to catch or kill the snake! Trying to handle the snake will most likely result in another bite, and is not necessary in order to ensure proper treatment. There are two basic types of antivenin - one for Coral Snakes and the other for pit vipers (rattlesnakes, Cottonmouth, Copperhead). Although a basic description of the snake may be helpful, the doctor will be able to determine which antivenin to use based on the symptoms of the victim. Also, do not attempt to differentiate the bite wound of venomous and non-venomous snakes in order to decide if you should seek immediate medical care.

As another note of caution, do not handle "dead" venomous snakes. Even snakes presumed to be dead can inject venom by reflex biting. In fact, one study found that rattlesnake heads were dangerous up to an hour after decapitation. 


\section{VENOMOUS SNAKEBITE AND PETS}

As with people, seeking prompt medical care is crucial for pets that are bitten by venomous snakes. Having an action plan ahead of time will facilitate your ability to get your pet the immediate medical treatment it needs. Treatment of venomous snakebite for pets is very similar to that for humans. Most likely your veterinarian will administer antivenin to counteract the toxic effects of the snakes venom. Your pet will also need to be hospitalized for several days so supportive care can be continued. Not all animal clinics carry antivenin or are equipped to provide the care your pet will need, so you should check with your veterinarians office ahead of time to ensure they are able to treat and care for your pet. If your regular veterinarian is unable to provide the care your pet requires, you should find the closest animal clinic that is equipped to do so. You should also find the closest emergency animal hospital (open 24 hours) that stocks antivenin in case your pet is bitten at a time when your regular clinic is closed.

If your pet is bitten, immediately call the appropriate animal hospital (see above) to advise them of the situation before you arrive. You will need to transport your pet to the animal hospital for treatment. If you have not previously verified that they have antivenin on hand and can give your pet the care it requires, do so now - if they are unable to treat your pet adequately, you should call an emergency clinic at this point. Keep your pet calm and comfortable, and limit its activity to a minimum. Get your pet to the car (carry your pet to the car if you can), and take it to the animal hospital as quickly as possible. According to an expert at the University of Florida's College of Veterinary Medicine, there is little you can do at home to treat your pet for a bite from a venomous snake, and you should not attempt any folk remedies.

If a pet does not receive prompt medical care at an animal clinic, its prognosis for recovery is poor, especially if the bite was from a Cottonmouth, Eastern Diamondback Rattlesnake, or Coral Snake. With prompt and adequate care, including delivery of antivenin, most dogs survive bites of Cottonmouths and Eastern Diamondback Rattlesnakes. Also, bites to

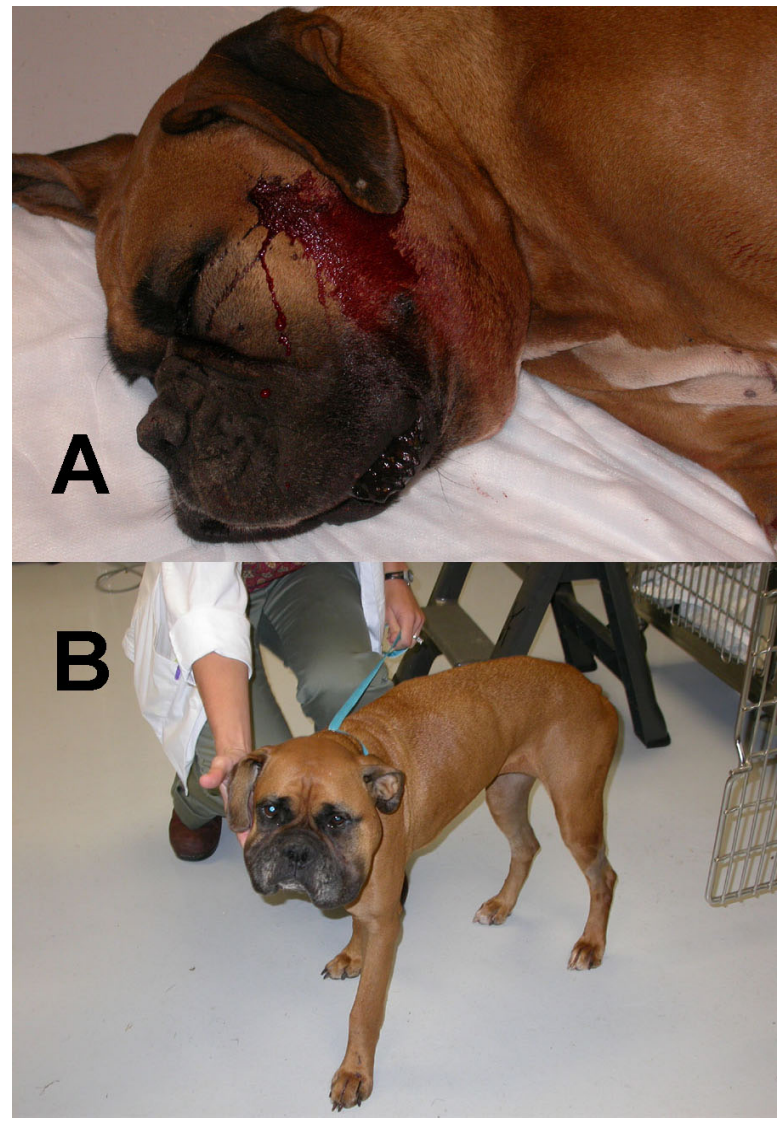

Figure 1. This boxer was bitten by an Eastern Diamondback Rattlesnake (a pit viper). When the dog arrived at the vet soon after the bite $(A)$, the bite was bleeding and beginning to swell, and the dog was highly lethargic. After receiving proper medical treatment $(B)$, this boxer was feeling much better and was able to return home. Credits: Michael Schaer, DVM, University of Florida

dogs by Pygmy Rattlesnakes and Copperheads are usually not fatal, according to a University of Florida expert, as long as supportive care is available.

One company has developed a venomous snake vaccine for dogs. The vaccine was developed for use against bites of venomous snakes native to the western U.S., and it has not been demonstrated to be indisputably effective for use against bites of venomous snakes native to the southeastern U.S. For more information, visit the manufacturers web site (http://www.redrockbiologics.com/) and be sure to consult your veterinarian to decide if this vaccine is right for your dog. Keep in mind that even if your dog is vaccinated, you should still seek immediate medical care for your dog if it is bitten by a venomous snake. 


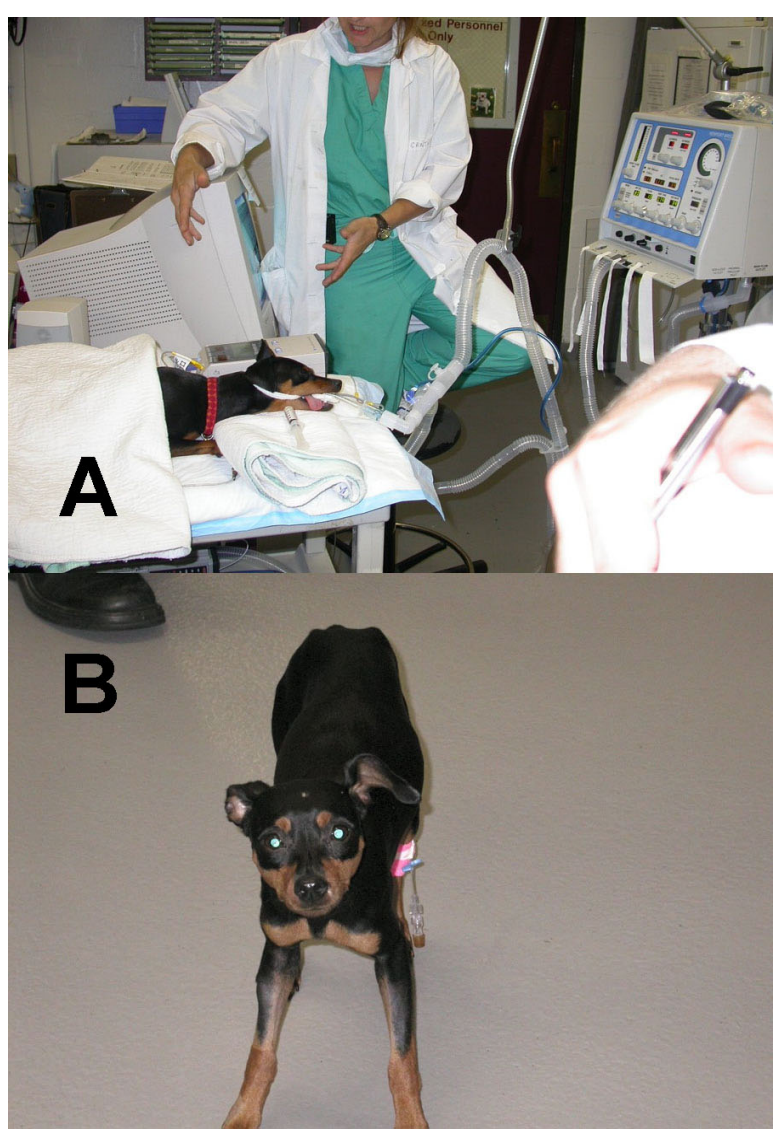

Figure 2. This Miniature Pinscher was bitten by a Coral Snake (an elapid). The dog became paralyzed, and was placed on life support with ventilator assistance (A). After receiving proper medical treatment, she recovered well $(B)$ and was able to return home. Credits: Michael Schaer, DVM, University of Florida

In many instances pet owners do not actually see their pet get bitten by a venomous snake. Therefore it is important to be able to recognize the symptoms of a venomous snakebite in your pet. Symptoms vary, depending on the type of venomous snake that inflicted the bite (see below). If a pet is bitten by a pit viper (rattlesnakes, Cottonmouth, Copperhead) the most obvious symptom will be localized swelling at the bite site. There may also be bleeding from the fang wounds and your pet will likely become quiet or lethargic (Figure 1). Most dogs are bitten on the head, neck, or muzzle, so a severely swollen face is an indication that the pet has been bitten by a pit viper. Cats are most often bitten on the body, rather than the head and face. Bites from Coral Snakes produce different symptoms, and the onset of symptoms may be delayed for several hours. Symptoms include weakness, vomiting, excessive salivation, and difficulty breathing (Figure 2). It is essential that your pet receive prompt medical care, including treatment with antivenin, for a bite from most pit vipers or a Coral Snake.

\section{WHAT TO EXPECT -- SNAKEBITE TREATMENT}

There are two basic types of snake venoms hemotoxic and neurotoxic. Symptoms and treatments in people are very similar to those for pets. Coral Snake venom is neurotoxic, affecting the nervous system. Coral Snake bites are generally not very painful, but are often accompanied by symptoms such as weakness, numbness around the bite, sweating, salivation, difficulty breathing, and even paralysis. The pit vipers (rattlesnakes, Cottonmouth, Copperhead) have hemotoxic venom, which attacks the tissues and the blood. Symptoms of a pit viper bite include intense pain, swelling, weakness, numbness/tingling, rapid pulse or cardiac arrhythmia, confusion, vomiting, and kidney failure.

After the victim arrives at the hospital (or emergency vet - treatment is similar for pets), they will be immediately given intravenous fluids and blood will be drawn for analysis. Lab analysis of the blood will allow doctors to evaluate the extent of the hemotoxic effects (damage to tissues and blood) of pit viper venom, including organ function. Pets are frequently also given intravenous antibiotics, in order to prevent bacteria (from the snakes mouth) from infecting the wound. The doctor (or veterinarian) will also monitor swelling by frequently measuring the bitten extremity. All venomous snakes can inflict what is known as a "dry bite"; biting without injecting venom. Doctors will continuously monitor the victims symptoms in order to determine if venom was actually injected.

If venom was delivered, the bite must be treated with antivenin, which can be rather expensive. There are two basic types of antivenin that are specific for either Coral Snake or pit viper venom. Before receiving the antivenin, the victim is often given an antihistamine intravenously to prevent or reduce possible allergic reactions to the antivenin. Depending on the symptoms, a human may receive as many as 25 (or more) vials of antivenin. Some 
people (or pets) can develop a hypersensitive (extreme) allergic reaction to the antivenin that must be treated with antihistamines and/or epinephrine. In the weeks following a venomous snakebite, some patients develop "serum sickness", which can be treated with systemic steroids.

Treatment for venomous snakebite can be rather expensive, and hospitalization of the patient for several days is likely. Patients may also require extensive rehabilitation, especially when muscle damage is severe. However, if medical attention is received soon after the bite occurs, chances of survival are excellent for both humans and pets. To ensure the well-being of yourself and your family members (pets included) it is important to be prepared and have an emergency action plan in the unlikely event of venomous snakebite.

\section{SAMPLE SNAKEBITE EMERGENCY PLAN}

The following is a sample snakebite emergency plan that you can fill out, discuss, and post in an accessible place so that household members and others (babysitters, visiting relatives, etc.) will have simple instructions to follow and all of the relevant information necessary to do so.

\section{IF A HUMAN IS BITTEN:}

1. Call 911 and ask for an ambulance

2. Call the poison control hotline, and give them the hospital name and number

3. Keep the victim calm, remove rings, watches and bracelets, keep the bite below the heart, and wash the bite with soap and water (if you have time)

4. Record the time of the bite and any symptoms

POISON CONTROL HOTLINE - 1-800-222-1222
1. Call the emergency vet

2. Keep the pet calm and limit activity - carry pet to the car

3. Take the pet to the vet ASAP!

4. Take a record of medicines, allergies, etc. with you to the hospital

ASPCA ANIMAL POISONING HOTLINE -

1-888-426-4435 (charges apply)

IN CASE OF SNAKEBITE EMERGENCY --

OUR ADDRESS:

NEAREST HOSPITAL -

Telephone

Address

Directions:

EMERGENCY VETERINARIAN -

Telephone (__

Address

Directions:

Date antivenin supply verified 


\section{FAMILY INFORMATION:}

1. NAME -

Medical Conditions -

Allergies -

Medicines Taken -

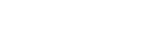

2. NAME -

Medical Conditions -

Allergies -

Medicines Taken -

\section{NAME -}

Medical Conditions -

Allergies -

Medicines Taken -

\section{NAME -}

Medical Conditions -

Allergies -

Medicines Taken -

\section{PET INFORMATION:}

Non-Emergency Vet -

Telephone (__

\section{PET NAME -}

Species/Description -

Medical Conditions -

Allergies -

Medicines Taken -

\section{PET NAME -}

Species/Description -

Medical Conditions -

Allergies -

Medicines Taken -

\section{ADDITIONAL RESOURCES}

This is the final document in a series of four documents by Dr. Steve Johnson and Monica McGarrity that provide information to Florida's residents on how to identify snakes that are commonly encountered in residential settings, how to prevent encounters from occurring in the first place, and how to respond in the unlikely event that someone is bitten by a snake. Anyone living in Florida, especially people new to the state, will find these documents useful. These documents are available online through UF/IFAS Extension Electronic Data Information Source)

1. Dealing With Snakes in Florida's Residential Areas - Introduction (http://edis.ifas.ufl.edu/UW257) 
2. Dealing With Snakes in Florida's Residential Areas - Identifying Commonly Encountered Snakes (http://edis.ifas.ufl.edu/UW258)

3. Dealing With Snakes in Florida's Residential Areas - Preventing Encounters (http://edis.ifas.ufl.edu/UW260)

4. Dealing With Snakes in Florida's Residential Areas - Emergency Planning (http://edis.ifas.ufl.edu/UW261)

\section{Hotline Numbers:}

Poison Control Hotline: 1-800-222-1222

American Society for the Prevention of Cruelty to Animals (ASPCA) Poisoning Hotline: 1-888-426-4435 (charges may apply)

\section{Good Books on Florida Snakes:}

Conant, R., and J. Collins. 1998. Peterson Field Guide to Reptiles and Amphibians of Eastern and Central North America, 3rd edition. Boston:

Houghton Mifflin Company.

Carmichael, P., and W. Williams. 2004. Florida's Fabulous Reptiles and Amphibians. Tampa: World Publications.

Tennant, A. 2003. Snakes of North America: Eastern and Central Regions. revised edition. Houston: Lone Star Books.

\section{Snake Resources on the World Wide Web:}

Johnson, S.A. 2005. Dealing with Venomous Snakes in Florida Schoolyards Series.

WEC199-202. Gainesville: Institute of Food and Agricultural Services.

http://edis.ifas.ufl.edu/

TOPIC_SERIES_Dealing_with_Venomous_Snakes_i

n_Florida_School_Yards

Johnson, S.A., and M.E. McGarrity. "Black

Snakes": Identification and Ecology. WEC214.

Gainesville: Institute of Food and Agricultural

Services. 2006. http://edis.ifas.ufl.edu/UW251

Florida Museum of Natural History-Online guide to Florida snakes: http://www.flmnh.ufl.edu/herpetology/

FLGUIDE/onlineguide.htm

Florida Fish and Wildlife Conservation

Commission snake

page:http://www.myfwc.com/critters/snakes.asp

Partners in Amphibians and Reptile

Conservation (PARC) site:

http://www.parcplace.org/index.html 